\title{
Effective communication at pre-anaesthetic evaluation clinic of a tertiary care hospital: patient perspectives and satisfaction
}

\author{
Kusha Nag ${ }^{1^{*}}$, Dewan Roshan Singh ${ }^{1}$, VR Hemanth Kumar ${ }^{2}$, T Sivashanmugam ${ }^{2}$ \\ Associate Professor ${ }^{1}$, Professor ${ }^{2}$, Mahatma Gandhi Medical College, Pondicherry, India.
}

\begin{abstract}
Background: Effective preoperative evaluation and communication with the patient is key to favourable perioperative outcome and patient satisfaction. This observational study aims to evaluate patient perspectives and satisfaction with communication at pre-anaesthetic evaluation clinic (PAC) of a tertiary care hospital.
\end{abstract}

\begin{abstract}
Methodology: All patients attending PAC during a period of three months were encouraged to fill a questionnaire and submit it in a drop box at the time of leaving the clinic. Responses were entered on a Microsoft excel sheet and analysed at the end of three months.
\end{abstract}

\begin{abstract}
Results: Out of 600 questionnaires distributed, with a response rate of $78.8 \%, 443$ were subjected to statistical analysis after excluding the incompletely filled questionnaires. 44.9\% patients had difficulty in locating PAC. $11.2 \%$ patients reported a waiting period of more than 20 minutes. Purpose of PAC was known to only $19.38 \%$ of patients prior to attending PAC. Only $38.83 \%$ patients were given an option to choose an anaesthetic technique. While $51.91 \%$ patients were explained the anaesthetic risk, $62.75 \%$ and $42.59 \%$ patients were explained surgical risk and risk associated with their comorbid condition respectively. $57 \%$ patients were explained about postoperative pain relief and given fasting instructions. $70.65 \%$ patients felt less anxious after visiting an anaesthesiologist while $73 \%$ patients felt that all their questions were adequately answered by the attending anaesthesiologist. $43.3 \%$ patients were not accepted as fit for anaesthesia in first PAC visit.

Conclusion: Patients presenting in PAC had poor prior knowledge about the purpose of PAC. Fewer patients were provided information on anaesthetic techniques available to choose from. Overall satisfaction in terms of reduction in anxiety and being adequately answered by anaesthesiologist at PAC was found to be good in our hospital.
\end{abstract}

Keywords: Pre-anaesthetic evaluation; patient satisfaction; patient perspective of PAC; preoperative anxiety

\section{Introduction}

Anaesthesiologist plays a decisive role in perioperative management of a surgical patient at various stages. ${ }^{1}$ To minimise perioperative risk we significantly depend on efficient preoperative evaluation and optimisation. There is enough evidence that an in-person assessment at preanaesthetic evaluation clinic (PAC) is associated with reduction of in-hospital morbidity and mortality as well as decreased cancellation rate., ${ }^{2,3}$ The aim of PAC is not just to clear the patients

*Correspondence: Kusha Nag

Email:kushanag@gmail.com

https://orcid.org/0000-0002-7922-6584

Received: 04/11/2017

Accepted:25/02/2018

DOI: http://doi.org/10.4038/slja.v26i2.8285 for surgery, rather to prepare them for it. This involves eliciting appropriate medical history, optimising comorbidities and risk stratification. Education of the patient about what to expect during perioperative period while giving them an opportunity to actively participate in decision making may ensure that the patient reaches operating room optimally prepared both medically as well as psychologically. This may ensure lesser anxiety, better co-operation and improved satisfaction. Patient satisfaction is a reliable measure of quality of patient care. Many factors contribute to patient satisfaction including accessibility and convenience of services, interpersonal relationships, competence of health professionals and patient expectations and preferences. ${ }^{4}$ Therefore we undertook a survey to analyse patient perception of communication and their satisfaction with the communication practices at pre anaesthetic evaluation clinic (PAC) of a tertiary care hospital in India. 


\section{Methodology}

This observational study was designed to determine patient satisfaction with the preoperative anaesthetic evaluation clinic at a tertiary care teaching hospital in India over a period of 3 months, from September 2016 to November 2016. A questionnaire was structured to record patient information such as demographics, followed by 19 questions (Table 1). After approval from the Institutional Human Ethical committee all patients between 18-80yrs, who were scheduled for elective surgery and visited the PAC during the data collection period were included. Patients with poor medical condition and mentally challenged were excluded. After obtaining a written informed consent patients were given the questionnaire in either English or Tamil. Patients were requested to fill up their responses (to choose the best appropriate option) and anonymously deposit the questionnaire in a drop box placed outside the PAC. A paramedic helped patients with no formal education who were unable to read the questionnaire to fill up their responses. At the end of 3 months, the drop box was opened and the responses were entered on a Microsoft excel sheet, analysed and results were expressed as percentages. Chi square test was used to test the association between information provided at PAC with patient perspective about their anxiety.

\section{Results}

A total of 600 patients were provided with the study questionnaire during a period of three months, out of which 473 were deposited back to the drop box. This shows a response rate of $78.8 \%$.

After excluding the incompletely filled questionnaires, 443 were subjected to statistical analysis. Average age of participants was $40 \pm$ $15 \mathrm{yrs}$ with maximum age of $80 \mathrm{yrs}$. There were 217 (48.9\%) male and 227 (51.2\%) female participants in the study. 332 patients $(25 \%)$ had received no formal education while 111 were educated formally $(75 \%)$.
Table 1: Study questionnaire

\begin{tabular}{|l|l|}
\hline S. No & QUESTIONS \\
\hline 1. & Did you find any difficulty in reaching this clinic? \\
\hline 2. & $\begin{array}{l}\text { If yes, tick the most appropriate reason } \\
\text { It is far from surgical OPD/ Ward } \\
\text { Not enough sign boards } \\
\text { No clear instructions from attending nurse/ } \\
\text { doctor from ward/OPD on how to reach here } \\
\text { Registration was over by the time you reached }\end{array}$ \\
\hline 3. & $\begin{array}{l}\text { What was the average waiting time } \\
\text { 0-10min }\end{array}$ \\
\hline 10-20 min \\
>20 min
\end{tabular}

While 224 patients (55.07\%) did not have any difficulty in locating the PAC, 199 patients (44.92\%) expressed that it was difficult to locate. The reasons being, PAC located far from surgical OPD/Ward $(58.29 \%)$, not enough sign boards (28.6\%), no clear instructions from attending nurse/ doctor from ward/OPD on how to reach there $(9.54 \%)$ and registration time was over by the time they reached PAC (3.51\%) (Figure 1A).

The average waiting time was less than $10 \mathrm{mins}$ in $66.59 \%$ of the cases, and $11.5 \%$ patients reported a waiting time of more than $20 \mathrm{mins}$ before they were seen by an anaesthesiologist.

The purpose of PAC was not known to $33 \%$ of patients. Out of the $67 \%$ patients who reported to know the purpose of attending PAC, only $19 \%$ correctly knew that it was for screening and optimisation of major medical illness prior to surgery (Table 2). 


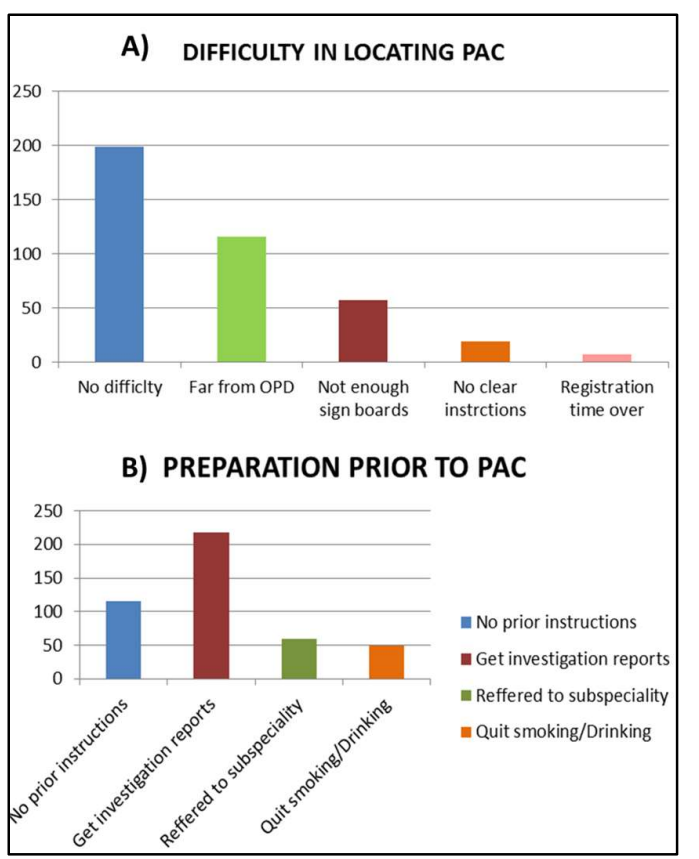

Figure 1:

A) Difficulty in locating PAC and its reasons

B) Patient preparation/ instructions prior to PAC

Table 2: Prior information about purpose of PAC

\begin{tabular}{|l|l|l|l|}
\hline \multicolumn{4}{|l|}{ Do you know the purpose of PAC? } \\
\hline No & Yes \\
\hline $149 / 443$ & $294 / 443(67 \%)$ & \multicolumn{2}{|l|}{} \\
\cline { 2 - 4 }$(33 \%)$ & $\begin{array}{l}\text { Yes, testing for } \\
\text { sensitivity to } \\
\text { anaesthetic } \\
\text { drugs before }\end{array}$ & $\begin{array}{l}\text { Yes,screening } \\
\text { and }\end{array}$ & $\begin{array}{l}\text { Yes,to } \\
\text { optimisation of } \\
\text { obajor medical } \\
\text { date for } \\
\text { surgery } \\
\text { administration } \\
\text { illness }\end{array}$ \\
\cline { 2 - 4 } & of anaesthesia & & \\
\cline { 2 - 4 } & 207/294 (70\%) & $57 / 294(19 \%)$ & $\begin{array}{l}30 / 294 \\
(10 \%)\end{array}$ \\
\hline
\end{tabular}

Instructions before attending $\mathrm{PAC}$ were given to $328(74.04 \%)$ patients (Figure 1 B).

The anaesthesiologists introduced themselves to $72.8 \%$ patients. $38.83 \%$ patients were explained about types of anaesthetic techniques available and given an option to choose. While 51.91\% patients were explained the problems and benefits associated with the anaesthetic technique planned for them, $62.75 \%$ and $42.59 \%$ patients were explained surgical risk and risk associated with their comorbid condition respectively. 57\% patients were explained about plan for postoperative pain relief and given fasting instructions.
$70.65 \%$ patients felt less anxious after visiting an anaesthesiologist while $75.39 \%$ were satisfied with the privacy in PAC. Patients who were explained about surgical risks and postoperative analgesic plan felt less anxious after visiting PAC. (Table 3) $73 \%$ of patients felt that all their questions were adequately answered by the attending anaesthesiologist.

43.3\% patients (192) did not receive fitness in first PAC visit the commonest reason was that patient did not bring reports (49\%) (Figure 2).

Figure 2: Reasons for delay in anaesthetic fitness

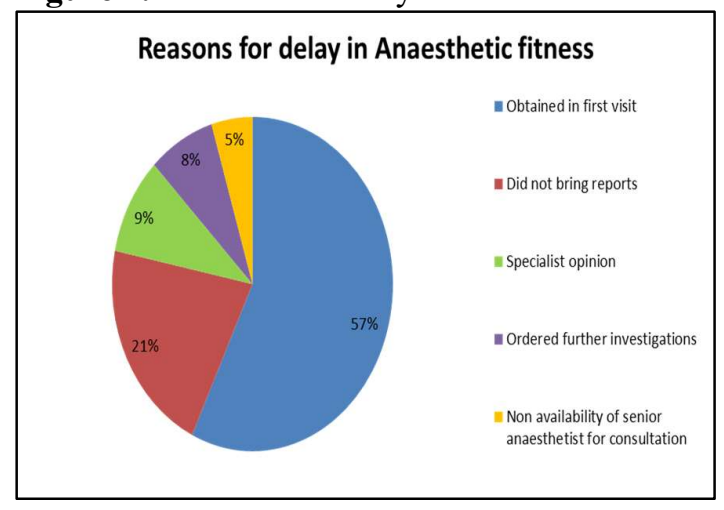

Table 3: Association between information provided at PAC and patient anxiety

\begin{tabular}{|c|c|c|c|c|}
\hline \multirow{2}{*}{\multicolumn{2}{|c|}{ Factors }} & \multicolumn{2}{|c|}{$\begin{array}{l}\text { Did you feel less } \\
\text { anxious after } \\
\text { visiting } \\
\text { anaesthesiologist? }\end{array}$} & \multirow{3}{*}{$\begin{array}{l}\mathbf{P} \\
\text { value } \\
0.17\end{array}$} \\
\hline & & Yes & No & \\
\hline \multirow{2}{*}{$\begin{array}{l}\text { Explained } \\
\text { anaesthetic } \\
\text { risk? }\end{array}$} & Yes & 170 & 61 & \\
\hline & No & 144 & 68 & \\
\hline \multirow{2}{*}{$\begin{array}{l}\text { Explained } \\
\text { surgical risk? }\end{array}$} & Yes & 279 & 0 & \multirow[t]{2}{*}{0.000} \\
\hline & No & 35 & 128 & \\
\hline \multirow{2}{*}{$\begin{array}{l}\text { Discussed post- } \\
\text { operative } \\
\text { analgesia plan? }\end{array}$} & Yes & 252 & 1 & \multirow[t]{2}{*}{0.000} \\
\hline & No & 62 & 127 & \\
\hline
\end{tabular}

\section{Discussion}

In our study, the questionnaire was designed to assess patient perspective based on: 1) Accessibility and convenience of registration process, 2) Prior knowledge of PAC and preparation before attending 3) Adequacy of communication and information provided at PAC and 4) Delay in receiving fitness at PAC and reasons for it. 


\section{1) Accessibility and convenience of registration process}

The most common reason was PAC being located far from surgical OPD/ Ward (Figure $1 \mathrm{~A}$ ). Ideally PAC should be easily accessible from the main entrance of the hospital on ground floor, in the main out - patient department block near surgical specialties. ${ }^{5}$ In our hospital the PAC is located in the operation theatre (OT) complex on the second floor for easy accessibility by anaesthesiologists from operating room during busy operating hours. However enough signboards and clear instructions from attending ward nurse could help patients reach PAC conveniently.

Average waiting time of less than 10 mins for majority of patients in our PAC could be because at our PAC there are dedicated paramedical staff to register patientsand collect patient information before actually being seen by an anaesthesiologist. $11.5 \%$ patients had to wait for more than 20mins before being attended to. This could be because the anaesthesiologist posted in PAC was also responsible for conducting cases at outreach unit of our hospital and was unavailable at PAC during that time. A screening questionnaire to be filled by patients in the waiting area and keeping separate timings for follow-up and new patients can significantly contribute to reducing the turn over time in PAC. ${ }^{5,6}$

\section{2) Prior information about purpose of $P A C$}

In our study, a significant percentage of patients did not know the purpose of attending PAC. Onlya very few correctly knew that it was for screening and optimisation of major medical illness prior to surgery (Table 2). Previous studies have also shown poor knowledge about the perioperative role of anaesthesiologists in India. ${ }^{7,8} \mathrm{~A}$ simple poster in the waiting area explaining the purpose of PAC and what to expect during the perioperative process may improve patient knowledge and satisfaction with PAC.

\section{3) Communication at PAC}

Anaesthesiologists in PAC introduced themselves to most patients. A formal selfintroduction and brief communication about their perioperative role by the attending anaesthesiologist may help improve patient trust. We found that very few patients were explained about types of anaesthetic techniques available and given an option to choose. In a study to evaluate level of patient satisfaction regarding the decision-making process authors have found that almost all patients who were informed of their choices for anaesthesia and involved in the decision-making process were satisfied and felt respected; the majority of patients preferred a collaborative role. ${ }^{9,10}$

While $51.91 \%$ patients were explained the problems and benefits associated with the anaesthetic technique planned for them, $62.75 \%$ and $42.59 \%$ patients were explained surgical risk and risk associated with their co-morbid condition respectively. We analysed if information provided at PAC had any role in reducing anxiety of patients and found that anxiety did not co-relate to information about anaesthetic technique $(\mathrm{p}=0.173)$. But patients who were provided information about surgical risk had greater reduction in their anxiety levels as compared to patients who were not explained about it $(\mathrm{p}=0.000)($ Table 3$)$.

A study on assessing role of preoperative information provided about surgery and anaesthesia on perioperative anxiety also found that information about surgery significantly reduces anxiety but anaesthesia information did not show any role in it. ${ }^{11}$ Hence, a brief communication about not just the anaesthetic risks and benefits but also surgical aspect is important in reducing patient anxiety.

We found that patients who were explained about their postoperative analgesia plan were significantly less anxious $(\mathrm{n}=252)$ after PAC as compared to those who were not $(n=1)$ (Table 3$)$. Fear of post-operative pain is one of the major factors for perioperative anxiety in previous studies. ${ }^{12-14}$ Our study proves effective discussion at PAC about postoperative pain management may help reduce anxiety among patients. A good percentage of patients felt that their questions were adequately answered at PAC which could have further contributed to reduction in anxiety after meeting the anaesthesiologist.

\section{4) Delay in getting accepted for surgery at $\mathrm{PAC}$ and reasons for it.}

43.3\% patients (192) did not get accepted for surgery in first PAC visit; commonest reason being unavailability of investigation reports. (Figure 2) 
Similar results were found by previous investigators who reported that $41 \%$ patients getting delayed anaesthetic fitness. ${ }^{1}$ The most common reasons expressed as inadequate control of pre-existing medical conditions, insufficient investigation and quantification of existing medical conditions and new acute illnesses such as pulmonary infection. ${ }^{15}$ Since delay in getting accepted for surgery is likely to cause considerable disruption to both the work and family life of patients, it is extremely important that adequate explanation is given by anaesthesiologist.

Limitation of our study was that we did not observe the role of seniority or experience of anaesthesiologist on information provided at $\mathrm{PAC}$ and anxiety levels of patients.

\section{Conclusion}

We found that in our PAC, very few patients were given the option to choose an anaesthetic technique for themselves. Information regarding anaesthetic, surgical risk and post- operative analgesia plan was provided to adequate percentage of patients. Overall, patients felt less anxious after visiting PAC, more so when surgical risk factors and postoperative analgesia plan is discussed with them in the preoperative assessment clinic.

\section{References}

1. Rathod Y, Devalkar P, Pawar P, et al. Study of Patient satisfaction in Anesthesia OPD of Tertiary Care Hospital. IOSR Journal of Dental and Medical Sciences 2015; 14: 66-76.

2. Blitz JD, Kendale SM, Jain SK, et al. Preoperative Evaluation Clinic Visit Is Associated with Decreased Risk of In-hospital Postoperative Mortality.Anesthesiology2016;125:28094https://doi.org/10.1097/ALN.000000000000119 $\underline{3}$ PMid:2743374

3. Hussain AM, Khan FA. Anaesthetic reasons for cancellation of elective surgical inpatients on the day of surgery in a teaching hospital. JPMA 2005; 55: 374.

4. Gebremedhn EG, Chekol WB, Amberbir WD, Flatie TD. Patient satisfaction with anaesthesia services and associated factors at the University of Gondar Hospital, 2013: a cross-sectional study. BMC Res Notes 2015; 8: 377-385. https://doi.org/10.1186/s13104-015-1332-4 PMid:26306394 PMCid:PMC4549915

5. Gupta A, Gupta N. Setting up and functioning of a preanaesthetic clinic. Indian J Anaesth. 2010; 54: 504-507. https://doi.org/10.4103/0019-5049.72638

PMid:21224966 PMCid:PMC3016569

6. Gupta A, Gupta N. Patient's experiences and satisfaction with preanesthesia services: A prospective audit. J AnaesthesiolClinPharmacol 2011;27:511-515.

https://doi.org/10.4103/0970-9185.86597

PMid:22096286 PMCid:PMC3214558

7. Jathar D, Shinde VS, Patel RD, Naik LD. A study of patients' perception about the knowledge of anaesthesia and anaesthesiologist. Indian $\mathrm{J}$ Anaesth. 2002; 46: 26-30.

8. Mathur SK, Dube SK, Jain S. Knowledge about Anaesthesia and Anaesthesiologist Amongst General Population in India. Indian $\mathrm{J}$ Anaesth. 2009;53(2):179-186. PMid:20640120 PMCid:PMC2900103

9. Hwang SM, Lee JJ, Jang JS, et al. Patient Preference and Satisfaction with Their Involvement in the Selection of an Anesthetic Method for Surgery. J Korean Med Sci 2014; 29 : 287-291.

https://doi.org/10.3346/jkms.2014.29.2.287 PMid:24550660 PMCid:PMC3924012

10. Falco D, Rutledge DN, Elisha S. Patient Satisfaction WithAnesthesia Care: What Do We Know? AANA Journal 2017; 85: 286-289.

11. Kiyohara LY, Kayano LK, Oliveira LM et al. Surgery information reduces anxiety in the preoperative period. Rev. Hosp. Clín. Fac. Med. S. Paulo 2004; 59: 51-56.

12. Ruhaiyem ME, Alshehri AA, Saade M et al. Fear of going under general anesthesia: A crosssectional study. Saudi J Anaesth. 2016; 10: 317321.

https://doi.org/10.4103/1658-354X.179094

PMid:27375388 PMCid:PMC4916817

13. Jawaid M, Mushtaq A, Mukhtar S, Khan Z. Preoperative anxiety before elective surgery. Neurosciences 2007; 12: 143-45.

14. Mc Cleane GJ, Cooper R. The nature of preoperative anxiety, Anaesthesia1990; 45:153-5. https://doi.org/10.1111/j.13652044.1990.tb14285.x

15. Milner Q. Fit for Anaesthesia? Surgery. 2002; 20: 49-53. https://doi.org/10.1383/surg.20.3.49.14618 